\title{
Psychosurgery, ethics, and media: a history of Walter Freeman and the lobotomy
}

\author{
James P. Caruso, BS, ${ }^{1}$ and Jason P. Sheehan, MD, PhD ${ }^{1,2}$ \\ Departments of ${ }^{1}$ Neurological Surgery and ${ }^{2}$ Radiation Oncology, University of Virginia Health System, Charlottesville, Virginia
}

At the peak of his career, Walter J. Freeman II was a celebrated physician and scientist. He served as the first chairman of the Department of Neurology at George Washington University and was a tireless advocate of surgical treatment for mental illness. His eccentric appearance, engaging personality during interviews, and theatrical demonstrations of his surgical techniques gained him substantial popularity with local and national media, and he performed more than 3000 prefrontal and transorbital lobotomies between 1930 and 1960. However, poor patient outcomes, unfavorable portrayals of the lobotomy in literature and film, and increased regulatory scrutiny contributed to the lobotomy's decline in popularity. The development of antipsychotic medications eventually relegated the lobotomy to rare circumstances, and Freeman's reputation deteriorated. Today, despite significant advancements in technique, oversight, and ethical scrutiny, neurosurgical treatment of mental illness still carries a degree of social stigma.

This review presents a historical account of Walter Freeman's life and career, and the popularization of the lobotomy in the US. Additionally, the authors pay special attention to the influence of popular literature and film on the public's perception of psychosurgery. Aided by an understanding of this pivotal period in medical history, neurosurgeons are poised to confront the ethical and sociological questions facing psychosurgery as it continues to evolve.

https://thejns.org/doi/abs/10.3171/2017.6.FOCUS17257

KEY WORDS psychosurgery; lobotomy; history of neurosurgery; Walter Freeman

$\mathrm{T}$ HE study and practice of neurosurgery uniquely positions its practitioners to explore the relationship between the brain and the mind. The history of neurosurgery includes many attempts to alter patients' moods and consciousness, ranging from trephination in $5000 \mathrm{BCE}$ to modern developments in neuromodulation. ${ }^{35}$ Of these procedures, few have achieved more publicity, and more infamy, than the lobotomy.

Academic and popular conceptions of the lobotomy, and of psychosurgery, derive in part from the work of Walter J. Freeman II, the first lobotomist in the US (Fig. 1). ${ }^{8}$ Freeman's methods were controversial, but his infectious energy and insatiable ambition led to the lobotomy's rapid acceptance and practice at psychiatric institutions across the US. However, many lobotomy patients suffered devastating postoperative complications, including intracranial hemorrhage, epilepsy, alterations in affect and personality, brain abscess, dementia, and death, ${ }^{8,24}$ and Dr. Freeman's star began to fade. Ominous portrayals of lobotomized pa- tients in novels, plays, and films further diminished public opinion, and the development of antipsychotic medications led to a rapid decline in lobotomy's popularity and Freeman's reputation.

Today, the lobotomy is rarely practiced, and Freeman's techniques are obsolete. Severe mental illness remains a substantial cause of disability in the US, ${ }^{11,22}$ lack of effective treatment poses a significant socioeconomic burden, ${ }^{11,22}$ and some patients prove resistant to the expanding arsenal of pharmacological treatment options. However, recent evidence demonstrates that some modern neurosurgical techniques provide safe and effective treatment for refractory obsessive-compulsive disorder (OCD) and major depressive disorder. ${ }^{27,41}$ Neurosurgery may retain an important role in psychiatric care, and Walter Freeman's legacy reveals ethical and social concepts that warrant substantial examination by neurosurgeons, researchers, administrators, and collaborating clinicians. Specifically, his practices illuminate the importance of patient safety,

ABBREVIATIONS OCD = obsessive-compulsive disorder; VA = Veterans Affairs. 


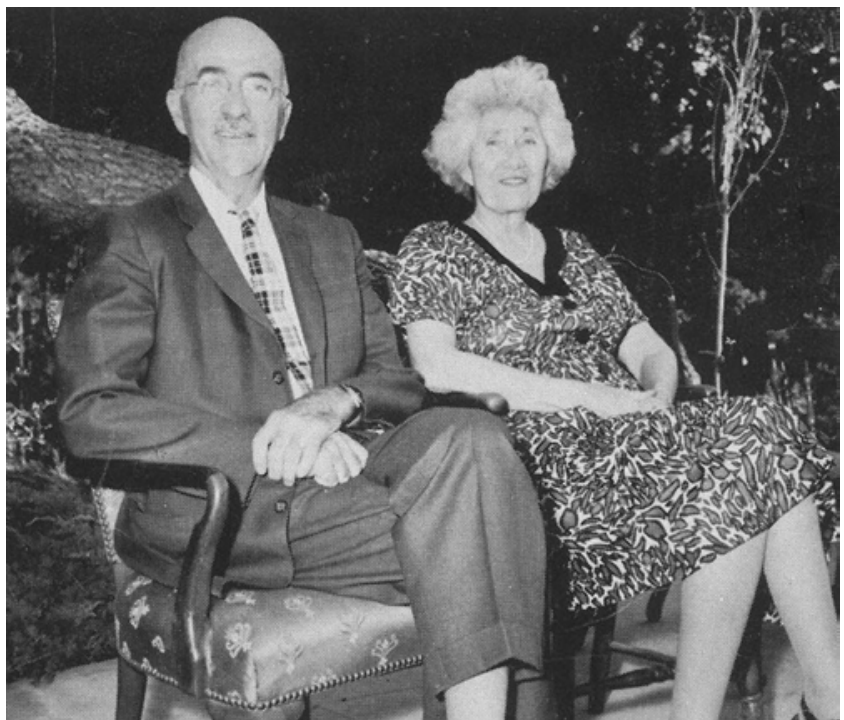

FIG. 1. Walter Freeman (1895-1972) with his wife. Source: Stanford University Medical Center Records (MSS 101), Stanford Medical History Center. Photograph available under the terms of the Creative Commons Licensing Agreement (https://creativecommons.org/licenses/ by-nc-sa/2.0/). File URL: https://www.flickr.com/photos/40390680@ N08/5159354954/in/photostream.

informed consent, postoperative care, and the portrayal of psychosurgery in popular media.

\section{Childhood and Education}

Freeman's prominent family influenced his decision to enter the medical field. His ancestors included physicians Lewis Morgan and Stephen Camp; the latter was a founder of the New Jersey Medical Society. ${ }^{8}$ Additionally, Freeman's maternal grandfather, William Williams Keen, was a pioneer in American neurological surgery. ${ }^{36}$ Keen served as a surgeon during the Civil War, performed the first resection of a primary brain tumor in the US in 1897, and served as medical consultant to presidents Grover Cleveland and Franklin Delano Roosevelt.

Freeman's flair for showmanship, and his propensity to clash with authority, became evident at a young age. He attended Yale University for his undergraduate education, and he created controversy after snapping a surreptitious photograph of a midnight meeting of the Scroll and Key Society, one of the oldest secret societies at Yale. ${ }^{8} \mathrm{He}$ submitted his photograph to the New York Times, where it was published despite political and legal pressure from society members.

After graduating from Yale in 1916, he attended the University of Pennsylvania Medical School, where he worked with William Spiller. Dr. Spiller's unequivocal dedication to teaching and research contributed to Freeman's interest in neurology. ${ }^{8,37}$ Freeman completed his neurology internship and residency at University Hospital in Philadelphia, but his early experiences as an intern were unfulfilling. He spent considerable time with neurosurgeon Charles Frazier, whose contributions to neurosurgery include the development of gasserian ganglion retroresection to treat trigeminal neuralgia and advancing neurosurgical strategies to treat intractable pain. ${ }^{4}$ Freeman marveled at Frazier's focus and resilience when operating, describing him as a man who stood "at the operating table for four and five hours, undertaking the most painstaking technical procedures." ${ }^{, 14}$ Although Frazier was not directly involved in Freeman's advancements in psychosurgery, Frazier's influence inspired him to practice neurology as a clinician and researcher. ${ }^{8}$

Freeman's early clinical experience also provided the foundations for his theatrical personality. In one instance, Freeman was assigned to treat a young man with a metal ring wrapped around his penis. ${ }^{8}$ Freeman briskly removed the ring with forceps, and when the patient requested the ring, Freeman told him it was kept as a surgical specimen. Instead, Freeman repaired the ring, engraved it with his family crest, and wore the ring on a gold chain for many years. Later, Freeman would be known for keeping memorabilia related to each patient that he treated with a lobotomy.

\section{Early Career and Partnership With James Watts}

After his internship and residency, Freeman became Director of Laboratories at St. Elizabeths Hospital in Washington, DC, a position he secured with the help of his grandfather Keen. ${ }^{8}$ Freeman desired a more traditional academic position, but he was not considered for an assistant professorship at the University of Pennsylvania. ${ }^{8}$ He was uncertain whether work at St. Elizabeths would afford him opportunities for academic advancement, but he was intrigued after learning that St. Elizabeths was a well-regarded institution for the insane. At St. Elizabeths, he developed a reputation for pursuing unconventional interventions to treat patients with catatonic schizophrenia and depression, including administering sodium amytal and manipulating patients' oxygen levels. He continued to keep detailed written and photographic records of his experiences with patients, and he developed an affinity for the cisternal tap. ${ }^{8,37}$ Although Freeman touted the procedure's speed and efficiency, calling it the "jiffy spinal tap," many colleagues criticized his reliance on the procedure, because it can cause severe neurological injury if performed improperly. ${ }^{8,37}$

As Freeman's career progressed, he held simultaneous faculty positions at Georgetown University and George Washington University. He hosted popular weekend autopsies for his students, which frequently involved audience participation and theatrical demonstrations. ${ }^{8}$ After becoming chairman of the Department of Neurology at George Washington University, he completed an MS and $\mathrm{PhD}$ in neuropathology at Georgetown, and he wrote one of the first comprehensive texts on neuropathology; $\mathrm{Neu}$ ropathology: The Anatomical Foundation of Nervous Diseases. ${ }^{8,16}$ In this text, he proposed that the structures of ganglionic cell nuclei differed in patients who died in manic versus depressive states. ${ }^{8,16}$ When discussing the text's chapter on neurosyphilis, he remarked "Friends tell me that [the chapter] is still the best in the English language, and I agree with them., $\$, 16,37$

At George Washington University, his professional rep- 
utation continued to grow, and he gave oral presentations and arranged medical exhibits at many prestigious venues, including national meetings at the American Medical Association and the American Academy of Neurology. ${ }^{8}$ His exhibits often included film screenings and pathological specimens in ornate display cases to captivate his colleagues. He began dressing with a distinctive style. He wore a wide-brimmed hat, long goatee, and round-rimmed glasses, he carried a cane, and he wore his engraved gold ring on a neck chain. ${ }^{8}, 37$ Additionally, he became a member of the Medical Society of the District of Columbia. ${ }^{8}$ Later in his career, when he became president of this society, he campaigned to allow nonwhite physicians to become members.

In 1935, Freeman recruited James Watts to join his practice at George Washington University. Watts would later become the first chairman of the Department of Neurological Surgery at George Washington and Freeman's primary partner in administering lobotomies. ${ }^{8}$ Freeman and Watts frequently corresponded with Egas Moniz, a Portuguese neurologist who pioneered the development of cerebral angiography and later won the Nobel Prize for his work on the development of the leucotomy. With Moniz's influence, Freeman and Watts became early advocates of the leucotomy. ${ }^{8,35}$

Moniz, and his neurosurgeon colleague Almeida Lima, performed the first leucotomy on March 3, 1936, and reported a case series of 20 patients who underwent the procedure for severe distortions of mood ${ }^{8,12,25,35}$ Moniz reported that, following leucotomy, 35\% of patients experienced complete relief of mental disturbance, $35 \%$ of patients benefitted from leucotomy but did not experience complete relief, and $30 \%$ of patients did not improve. ${ }^{8,25}$ Aware of the revolutionary potential of this surgery, Freeman and Watts prepared to perform the procedure in the US. In a letter to Moniz in May 1936, Freeman wrote, "I enjoyed particularly your recent work on the reduction of psychotic symptoms following operation on the frontal lobe. And I am going to recommend a trial of this procedure in certain cases that come under my care." 8,15 Moniz's response was gracious. He replied "I was very satisfied with your disposition to make the pre-frontal operation in certain psychoses," sent Freeman contact information for leucotome suppliers, and enclosed a copy of his most recent textbook with the inscription "To Dr. Walter Freeman of Washington, with kindest regards from Egas Moniz." 8,26 Later, Freeman's relationship with Moniz would take a more familiar tone. He would refer to Moniz as "Cher Maitre" (Dear Master) in personal correspondence, and Moniz's Nobel Prize in 1949 was driven by Freeman's nomination and advocacy. ${ }^{8}$

\section{Popularization of the Lobotomy and the "Icepick" Method}

On September 4, 1936, at George Washington University, Freeman and Watts performed the first lobotomy in the US on Alice Hood Hammatt, a woman diagnosed with agitated depression. ${ }^{8,17,35}$ Hammatt attempted to withdraw her consent the night before the operation, due to concerns about her head being shaved prior to the operation, so Freeman told her that he would not shave her head. ${ }^{8}$ On the day of the operation she continued to resist, and she struggled while she underwent sedation and general anesthesia.

For this procedure, and for many of the early prefrontal lobotomies, Freeman and Watts acted as cosurgeons. ${ }^{8}$ Watts provided neurosurgical expertise, Freeman dictated the pace and progression of the procedure, and both contributed an extensive knowledge of neuroanatomy. After creating a sterile field, they used gentian violet to mark the locations for 2 bur holes, one on each side of the skull over the frontal lobes. ${ }^{8,17}$ Incisions $3 \mathrm{~cm}$ in length were made at these locations, and self-retaining retractors were applied to stop scalp bleeding. Using an auger, Freeman and Watts created the bur holes and used a modified version of Moniz's leucotome, a cylindrical metal insert, to remove cores of white matter tracts between the prefrontal cortex and the thalamus. ${ }^{8,10,17,35}$ A wire loop protruded from the bottom end of the leucotome, and when Freeman and Watts rotated the leucotome, the loop excised a circular section of white matter. ${ }^{8,17}$ They excised white matter at depths of 4,3 , and $2 \mathrm{~cm}$, repositioned the leucotome at a different angle, and excised 3 more cores at equivalent depths. This process was performed bilaterally. They lacerated a single vessel during the final core excision, but the patient's vital signs did not demonstrate distress. The wounds were washed with saline, black silk sutures were used to seal the wounds, and the procedure was finished after approximately 1 hour.

When Hammatt awoke postoperatively, she stated that she was "happy," and she did not mind that Freeman had shaved her head. ${ }^{8}$ Six days after the operation, Hammatt experienced transient language difficulties, disorientation, and agitation, but she returned home, and Freeman considered the outcome a success. , $10,17,35$ Freeman's reputation grew, and his work was often highlighted in popular media outlets (Figs. 2-4). In preparation for a Southern Medical Association conference, Freeman invited Tom Henry, a science writer for the Washington Evening Star, to visit George Washington University, discuss advancements in psychosurgery, and observe a prefrontal lobotomy. ${ }^{8}$ Shortly after, Henry published an article that declared the lobotomy "probably constitute[s] one of the greatest surgical innovations of this generation." ${ }^{19} \mathrm{He}$ added, "It seems unbelievable that uncontrollable sorrow could be changed into normal resignation with an auger and a knife." Two months after Alice Hammatt's surgery, Freeman began describing the procedure as a "lobotomy" rather than a "leucotomy." The new terminology emphasized that the surgery was localized to the frontal lobes and involved the disruption of gray and white matter. Additionally, the semantic distinction allowed Freeman and Watts to distinguish their surgeries from those of Moniz and Lima. ${ }^{8}$ By 1942, Freeman and Watts had performed approximately 200 frontal lobotomies, and they published their first major case series. ${ }^{35}$ They reported that $63 \%$ of patients showed improvement following lobotomy, $23 \%$ of patients demonstrated no change in symptoms, and $14 \%$ of patients suffered severe postoperative deficits or death. The Saturday Evening Post promoted Freeman's ideas with resplendent optimism, writing "a world that once seemed the abode of 


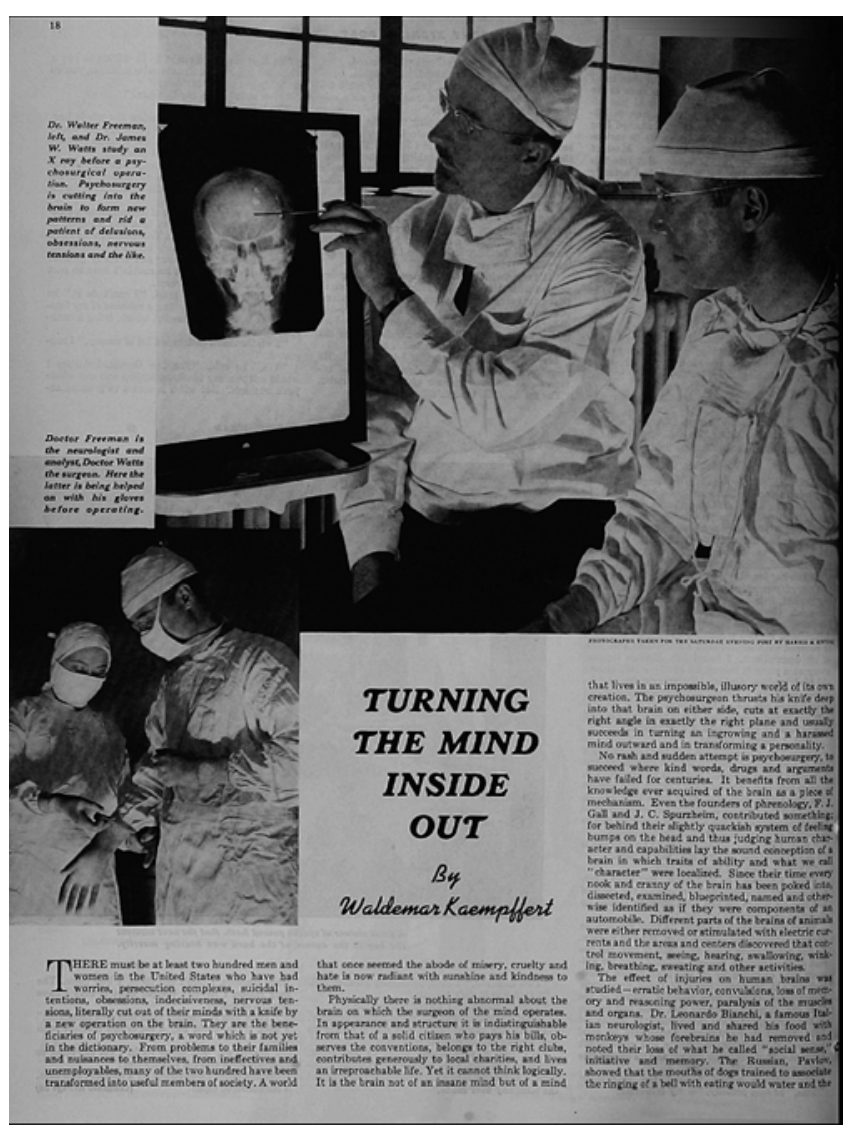

FIG. 2. First page of a magazine article profiling Walter Freeman, James Watts, and the popularization of the prefrontal lobotomy. Source for text: Waldemar Kaempffert; source for photography: Harris A Ewing (Saturday Evening Post, 24 May 1941, pages 18-19). Photograph available in the public domain via Wikimedia Commons. File URL: https://commons. wikimedia.org/wiki/File\%3ATurning_the_Mind_Inside_Out_Saturday_ Evening_Post_24_May_1941_page_18.jpg.

misery, cruelty, and hate is now radiant with sunshine and kindness." 32

After his early success performing frontal lobotomies, Freeman developed a transorbital approach based on the work of Amarro Fiamberti, as detailed in Robison et al. ${ }^{35}$ In Freeman's transorbital lobotomy, he used a mallet to tap an orbitoclast (a slender rod shaped like an icepick) through the orbital roof. ${ }^{34,35}$ Following penetration of the orbital roof, Freeman would sweep the orbitoclast laterally to obliterate frontal lobe tissue. ${ }^{8,34,35}$ Additionally, he was able to perform the procedure in an office setting because he anesthetized patients with a portable electroshock machine. ${ }^{8}$ Previously, Freeman required Watts' neurosurgical expertise to perform prefrontal lobotomies. His decision to perform a single prefrontal lobotomy without neurosurgical assistance was met with staunch criticism. Watts recalled that the hospital reprimanded Freeman, stating that he was "not a surgeon and if he wants to operate he'll have to apply for surgical privileges." ${ }^{8,40}$ However, because Freeman developed the transorbital lobotomy as an outpatient procedure that did not require any bur holes or general anesthesia, his lack of neurosurgical training did not preclude him from performing the operation by himself. After

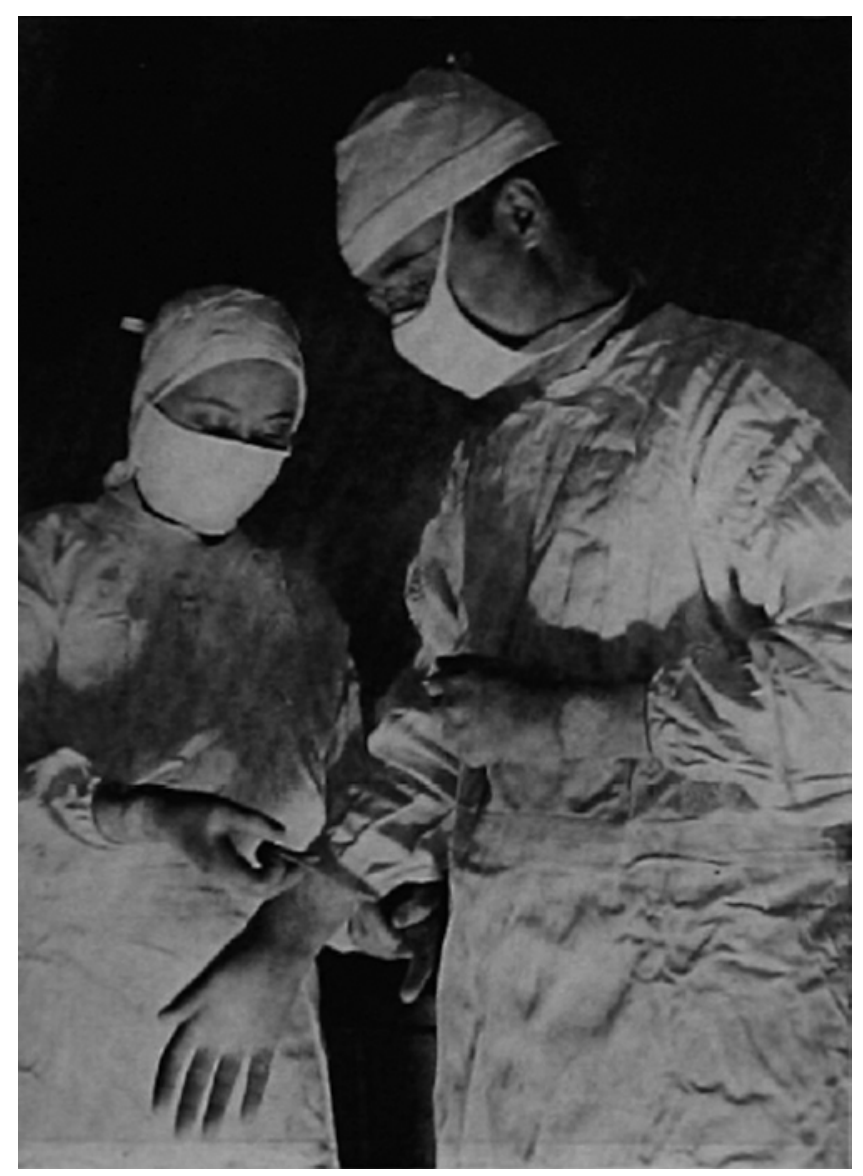

FIG. 3. James Watts preparing to begin surgery. Source for photography: Harris A Ewing (Saturday Evening Post, 24 May 1941, pages 18-19). Photograph available in the public domain via Wikimedia Commons. File URL: https://commons.wikimedia.org/wiki/File\%3ATurning the_Mind_Inside_Out_Saturday_Evening_Post_24_May_1941_a_detail_2.jpg.

Freeman performed his first transorbital lobotomy on Ellen Ionesco, a woman who suffered from bouts of manic depression and suicidal ideation, ${ }^{8}$ he penned editorials and gave numerous interviews promoting the procedure. ${ }^{7,8,35}$

Unfortunately, Watts did not favor the transorbital method, and this difference of opinion contributed to the end of their partnership. ${ }^{8,35}$ Watts resisted the technique itself, Freeman's lack of sterile technique when performing it, and the idea of performing the procedure in an outpatient setting. The conflict culminated in an intense disagreement over the treatment of Freeman's 10th transorbital lobotomy patient. According to Freeman, Watts observed the procedure and voiced his disapproval by threatening to leave their practice if Freeman did not stop performing the procedure. ${ }^{8}$ However, by Watts' account of the events, he had requested that Freeman not perform the procedure in their shared outpatient offices. Despite this request, Watts entered an office and discovered Freeman standing over an unconscious patient who had an icepick lodged in his orbit. Freeman asked Watts to assist him while he took a photograph. Watts refused, and he informed Freeman that he would actively campaign against transorbital lobotomies being performed at George Wash- 


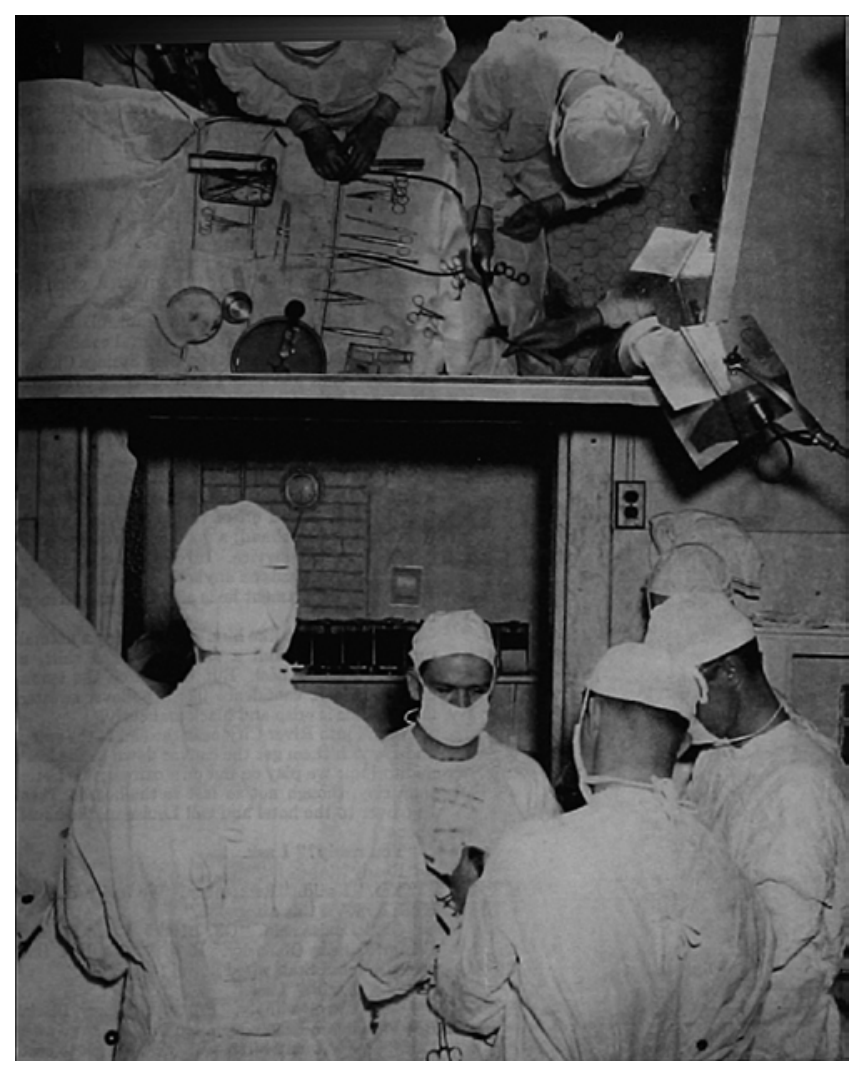

FIG. 4. James Watts and staff performing a prefrontal lobotomy. Source for photography: Harris A Ewing (Saturday Evening Post, 24 May 1941, pages 18-19). Photograph available in the public domain via Wikimedia Commons. File URL: https://commons.wikimedia.org/wiki/ File\%3ATurning_the_Mind_Inside_Out_Saturday_Evening_Post_24_ May_1941_b_detail.jpg.

ington University. When Freeman broached the idea of teaching psychiatrists to perform transorbital lobotomies, Watts adamantly objected. Freeman began working with a new neurosurgical partner, and their clinical partnership was effectively over.

\section{Media Stigma and a Fall From Grace}

Eventually, inconsistent outcomes contributed to negative public and regulatory sentiment against Freeman's work, and his reputation could not mitigate discouraging postoperative results. His lobotomy on Rosemary Kennedy, sister of President John F. Kennedy, remains one of his most prominent failures. As a child and young adult, Kennedy suffered from mild developmental delays that impaired her performance in school. ${ }^{8}$ As she grew older, she became more anxious and agitated, and she may have developed epilepsy in her teen years, so her father, Joseph Kennedy, employed Freeman and Watts to lobotomize her. Following the procedure she became severely disabled, was unable to function independently, and was institutionalized for the remainder of her life. One of Ms. Kennedy's nurses, who observed the procedure, found it so horrific that she left the medical profession entirely.

Neurosurgical and psychiatric authorities consistently mounted criticism of his methods, as evidenced by the controversy surrounding the adoption of Freeman's methods at Veterans Affairs (VA) hospitals. In 1948, Freeman was invited to demonstrate the transorbital lobotomy on patients at a VA hospital in Tuskegee, Alabama. ${ }^{32}$ The VA chief of psychiatric education mocked Freeman's liberal use of the procedure, remarking that "a pain in the neck" might qualify as an additional indication, and a VA consultant who practiced as an army neurosurgeon opposed the use of transorbital lobotomies on the grounds that Freeman "has published no article on the subject in the national literature," so he "[knew] nothing of the dangers, complications, or results." The national neurosurgical consultant to the VA stated that nonsurgeons would perform lobotomies at VA hospitals "over [his] dead body." Despite this fervent opposition, the VA's psychiatric chief permitted individual hospitals to determine whether psychiatrists were allowed to perform transorbital lobotomies. Foreboding depictions of mental institutions, lobotomized patients, and corrupt mental health officials in literature and film also influenced public disenchantment with the lobotomy. In 1958, the Tennessee Williams play Suddenly, Last Summer debuted on Broadway. The one-act production focuses on a young woman who is subjected to psychiatric evaluation following her cousin's death. ${ }^{42}$ Her wealthy aunt, who desires to keep secret the lurid circumstances of the death, maneuvers to have the young woman subjected to an involuntary lobotomy. The play depicts psychosurgery as a looming threat to vulnerable patients who do not cooperate with the interests of duplicitous family members. Williams's depiction of mental health institutions and psychosurgery is likely to have been related to his family history. His sister, Rose Williams, was diagnosed with paranoid schizophrenia and lobotomized at a young age. She was unable to function independently after the operation, and she spent her life institutionalized.

Following Williams's work, Sylvia Plath's The Bell Jar was released in $1963 .{ }^{33}$ The novel follows a young and intelligent woman with steadily worsening depression who eventually receives electroconvulsive therapy. During her stay in a mental institution, she encounters another woman who has undergone a lobotomy, whose face carries an expression of "perpetual marble calm." The lobotomized woman explains that she was angry and belligerent, but after her procedure, she is at peace with living within the confines of the institution. Despite the lobotomy's apparent success, Plath characterizes the patient as defeated and stripped of vitality and spirit.

Perhaps the most famous artistic portrayal of a lobotomized patient is Jack Nicholson's performance in One Flew Over the Cuckoo's Nest in $1975 .{ }^{13}$ Nicholson's character foments rebellion within a mental institution and encourages other patients to flout the institution's conventions and seek pleasure and enjoyment. After engaging in numerous power struggles with abusive medical staff, he is subjected to an involuntary lobotomy. He returns from the procedure with a blank expression and scars on his forehead. The film won 5 major Academy Awards, including Best Picture, and it solidified public perception of psychosurgery as a tool for wielding power over mentally ill patients and eliminating management problems in mental institutions. 
More recent portrayals of lobotomy in film include Frances ${ }^{6}{ }^{6}$ a fictionalized biopic of actress Frances Farmer released in 1982. In the film, Farmer undergoes an involuntary transorbital lobotomy after enduring ignominious physical and sexual abuse at the hands of mental institution staff. Her face is bloodied and bruised, and dozens of spectators watch as her lobotomist gives an animated lecture about the procedure. He is dressed in hospital garb, wears glasses, and his facial hair is similar to Walter Freeman's.

In 1955, chlorpromazine was approved for use in the US. Freeman's practice began to slow, and further media exposure tarnished his image. In one instance, he posed for a photograph during a transorbital lobotomy case, and the orbitoclast diverged from its intended path, causing the patient to hemorrhage and die immediately. ${ }^{8}$ His final transorbital lobotomy patient, Helen Mortensen, died 3 days after her operation in 1967. ${ }^{8,37}$ Despite these setbacks, Freeman did not abandon his quest to preserve his legacy. He continued to tour the country to give lectures, and he visited many of his former patients to follow up on their progress. He often took pictures to document their wellbeing. ${ }^{8,32}$ However, his lobotomy techniques are no longer practiced in the US. Although approximately 60,000 lobotomies were performed between 1936 and 1956 in the US, some of them in makeshift operating rooms outside of the hospital, lobotomies are now only performed under very select conditions and circumstances ${ }^{35}$ Furthermore, lobotomy portrayals in film and literature have led patients and physicians to regard psychosurgery with suspicion and skepticism. When Walter Freeman performed lobotomies, his questionable patient selection and unrefined neurosurgical technique led to dire consequences for some of his patients. He often failed to recognize the limitations of his methods, and he disregarded prevailing opinions in the psychiatric and neurosurgical communities, which revealed a lack of investment in multidisciplinary patient care. Since Freeman's time, collaboration in patient care has become an essential component of neurosurgical treatment of psychiatric disorders.

\section{Ethical Considerations and the Future of Psychosurgery}

Techniques in psychosurgery continue to evolve, and invasive ablative procedures like the lobotomy have been superseded by procedures such as deep brain stimulation that modulate neural function without destroying tissue. ${ }^{1,3,20,27}$ Additionally, minimally invasive ablative procedures, such as stereotactic radiosurgery, retain a prominent role is affording patients relief from the symptoms of intractable OCD. A study of 5 patients who underwent bilateral anterior capsulotomy with Gamma Knife radiosurgery for refractory OCD revealed that 4 patients demonstrated marked clinical improvement, and the remaining patient demonstrated mild clinical improvement, as measured by reductions in Yale-Brown Obsessive-Compulsive Scale scores. ${ }^{39}$ The median follow-up time was 24 months (range 6-33 months), and the patients suffered no adverse effects following radiosurgery. Figure 5 shows a treatment planning image for a patient who was treated for intractable OCD with Gamma Knife bilateral anterior capsulotomy.

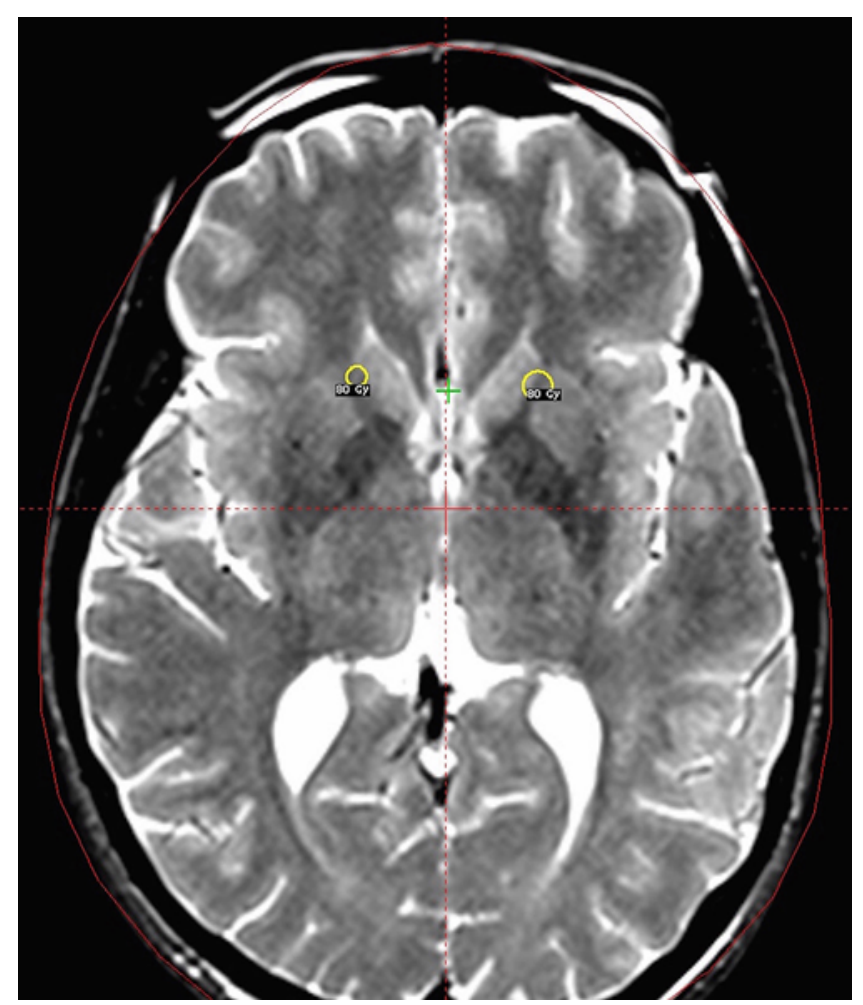

FIG. 5. Axial MR image demonstrating radiation dose plan for Gamma Knife bilateral anterior capsulotomy for intractable OCD.

Additionally, given the recent use of focused ultrasound for ablative treatment of essential tremor, ${ }^{9}$ proof-of-concept studies have explored using this technology to treat refractory OCD. ${ }^{21}$ Despite Freeman's controversial legacy, his neurosurgeon contemporaries continued to recognize the therapeutic potential of psychosurgery, and they refined and modified Freeman's conception of the frontal lobotomy. In 1949, William Beecher Scoville pioneered methods of orbital undercutting, which separated abnormal cortex from normal white matter tracts and facilitated targeted ablation of abnormal tissue. ${ }^{38}$ The same year, Lars Leksell introduced a stereotactic system designed to treat psychiatric disorders, and Leksell and Jean Talairach, creator of the Talairach neurosurgery coordinate system, codeveloped the anterior capsulotomy. ${ }^{23,35}$

Although current technical advances show great promise, rigorous analyses of ethical and sociological topics remain imperative, because studies of lobotomy practice in the US reveal a multitude of ethical quandaries. An epidemiological analysis of Stockton State Hospital's lobotomy program revealed that 245 lobotomies were performed on 232 patients between 1947 and 1954, before the introduction of chlorpromazine and reserpine led to the program's termination..$^{5}$ Of the 245 lobotomies, 205 (84\%) were performed on women. However, the hospital had more male patients, and more men were diagnosed with schizophrenia, a primary indication for lobotomy at the time. These disparities were not present for other interventional psychiatric treatments. Over the same time period, women and men underwent electroconvulsive therapy at the same rate. Scrutiny of individual patients' medical records re- 
vealed that physicians' need to "maintain order" in the hospital was a common reason to recommend lobotomy. One patient's record revealed that her "strange behavior," specifically her ambivalent attitude regarding child care, influenced her physicians' decision to lobotomize her. These findings demonstrate that future study of psychosurgery should include an assessment of the relationship between patient sex and disparities in psychiatric care.

It is also important to note that performing psychosurgery to alter personality, rather than to treat pathology, has historical precedents. Recent evidence revealed that Eva Peron underwent a prefrontal lobotomy in 1952 to alleviate metastatic cancer pain, ${ }^{29}$ but further analysis revealed that her lobotomy may have been politically motivated. ${ }^{28}$ Specifically, direct correspondence with members of Eva Peron's medical team suggests that Peron became increasingly belligerent and anxious as she neared the end of her life. Her increasingly aggressive political speeches reflected her change in demeanor, and her husband Juan Peron, the president of Argentina at the time, may have perceived her behavior as a political threat and ordered her lobotomy to permanently pacify her.

To address many of the ethical concerns in psychosurgery, researchers have developed a number of helpful guidelines. In 1981, Gostin proposed reasonable standards necessary to authorize psychosurgery. ${ }^{18}$ Among them, psychosurgery should be considered only after trying or considering less invasive therapeutic measures. Physicians must pay special attention to patients' ability to provide full consent; clinical research studies should confirm the intervention's safety and efficacy; and the risk of adverse change in personality should not exceed the degree of benefit that the treatment could confer. Similarly, the Oxford Neuroethics Gold Standard Framework provides a rigorous set of conditions, qualifications, and discussion points for researchers studying deep brain stimulation in patients with severe and enduring anorexia nervosa, ${ }^{31}$ and Nuttin et al. provide ethics guidelines developed by leading figures in stereotactic and functional neurosurgery. ${ }^{30}$ These frameworks emphasize rigorous assessments of patients' suitability for treatment and their capacity to consent. Additionally, the guidelines encourage multidisciplinary collaboration in treatment, assessments of patients' living conditions to ensure ideal postoperative support, and awareness of potential conflicts of interest among physicians, researchers, and funding sources. ${ }^{30,31}$ Prior analyses demonstrate that without stringent ethical standards, neuromodulation can provide little clinical benefit and lead to adverse outcomes. ${ }^{2}$

Public stigmatization of psychosurgery is another substantial obstacle that physicians must address. In many of the novels, plays, and films discussed earlier, psychosurgery robs the patients of their autonomy and strips them of their individuality. Alternatively, the surgeries are often performed out of desperation, with the express purpose of normalizing the characters to fit the constraints of an oppressive environment. These portrayals can undermine attempts to study the efficacy of newer neurosurgical therapies and impair physicians' ability to recruit patients for research studies. As a result, physicians should take proactive steps to combat the demonization of psychosurgery in popular media. Additionally, when treating patients with mental health disorders, physicians must consider neurosurgical interventions with care, diligence, and concern for the patient's safety and well-being.

\section{Conclusions}

The field of psychosurgery was founded on Walter Freeman's contributions, and his legacy remains ingrained in the collective consciousness of those who seek to treat mental disorders with neurosurgical interventions. His contributions to the field were prescient, but his incautious methods ultimately contributed to his decline in reputation. In particular, numerous dramatic characterizations of the lobotomy in literature and film contributed to the stigmatization of psychosurgery. Although psychosurgery now includes more humane and less invasive means of treating mental disorders, Freeman's complicated legacy provokes ethical and sociological discussions that remain relevant to the field.

\section{References}

1. Alonso P, Cuadras D, Gabriëls L, Denys D, Goodman W, Greenberg BD, et al: Deep brain stimulation for obsessivecompulsive disorder: a meta-analysis of treatment outcome and predictors of response. PLoS One 10:e0133591, 2015

2. Baumeister AA: The Tulane Electrical Brain Stimulation Program a historical case study in medical ethics. J Hist Neurosci 9:262-278, 2000

3. Bergfeld IO, Mantione M, Hoogendoorn ML, Ruhé HG, Notten P, van Laarhoven J, et al: Deep brain stimulation of the ventral anterior limb of the internal capsule for treatmentresistant depression: a randomized clinical trial. JAMA Psychiatry 73:456-464, 2016

4. Boockvar JA, Virella A, Kotapka M, Flamm ES, Grady MS: Neurosurgery at the University of Pennsylvania Medical Center. Neurosurgery 46:1223-1228, 2000

5. Braslow JT, Starks SL: The making of contemporary American psychiatry, Part 2: therapeutics and gender before and after World War II. Hist Psychol 8:271-288, 2005

6. Clifford G (director): Frances [film]. Universal City, CA: Universal Pictures, 1982

7. Diefenbach GJ, Diefenbach D, Baumeister A, West M: Portrayal of lobotomy in the popular press: 1935-1960. J Hist Neurosci 8:60-69, 1999

8. El-Hai J: The Lobotomist: A Maverick Medical Genius and His Tragic Quest to Rid the World of Mental Illness. Hoboken: Wiley, 2005

9. Elias WJ, Lipsman N, Ondo WG, Ghanouni P, Kim YG, Lee W, et al: A randomized trial of focused ultrasound thalamotomy for essential tremor. N Engl J Med 375:730-739, 2016

10. Faria MA Jr: Violence, mental illness, and the brain-a brief history of psychosurgery: part 1-from trephination to lobotomy. Surg Neurol Int 4:49, 2013

11. Feldman R, Bailey RA, Muller J, Le J, Dirani R: Cost of schizophrenia in the Medicare program. Popul Health Manag 17:190-196, 2014

12. Feldman RP, Goodrich JT: Psychosurgery: a historical overview. Neurosurgery 48:647-659, 2001

13. Forman M (director): One Flew Over the Cuckoo's Nest [film]. Beverly Hills: United Artists, 1975

14. Freeman W: Charles H. Frazier, in Walter Freeman and James Watts Collection, 1918-1988, Collection No. MS0803.UA. Washington, DC: George Washington University Special Collections Research Center (https://library.gwu. edu/ead/ms0803.xml) [Accessed July 10, 2017] 
15. Freeman W: Letter from Walter Freeman to Egas Moniz, May 25, 1936, in Walter Freeman and James Watts Collection, 1918-1988, Collection No. MS0803.UA. Washington, DC: George Washington University Special Collections Research Center (https://library.gwu.edu/ead/ms0803.xml) [Accessed July 10, 2017]

16. Freeman W: Neuropathology: The Anatomic Foundation of Nervous Diseases. Philadelphia: W.B. Saunders, 1933

17. Freeman W, Watts J: Prefrontal lobotomy in the treatment of mental disorders. South Med J 30:23-31, 1937

18. Gostin LO: Psychosurgery: a hazardous and unestablished treatment? A case for the importation of American legal safeguards to Great Britain. J Soc Welfare Law 4:83-95, 1982

19. Henry T: Brain operations by D.C. doctors aids mental ills. Washington Evening Star. November 20, 1936.

20. Jimenez F, Nicolini H, Lozano AM, Piedimonte F, Salin R, Velasco F: Electrical stimulation of the inferior thalamic peduncle in the treatment of major depression and obsessive compulsive disorders. World Neurosurg 80:S30.e17-S30. e25, 2013

21. Jung HH, Kim SJ, Roh D, Chang JG, Chang WS, Kweon EJ, et al: Bilateral thermal capsulotomy with MR-guided focused ultrasound for patients with treatment-refractory obsessivecompulsive disorder: a proof-of-concept study. Mol Psychiatry 20:1205-1211, 2015

22. Lee S, Rothbard A, Choi S: Effects of comorbid health conditions on healthcare expenditures among people with severe mental illness. J Ment Health 25:291-296, 2016

23. Leksell L: The stereotaxic method and radiosurgery of the brain. Acta Chir Scand 102:316-319, 1951

24. Miller A: The lobotomy patient-a decade later: a follow-up study of a research project started in 1948. Can Med Assoc J 96:1095-1103, 1967

25. Moniz E: Essai d'un traitement chirurgical de certaine psychoses. Bull Acad Med 115:385-392, 1936

26. Moniz E: Letter from Egas Moniz to Walter Freeman, June 24, 1936, in Walter Freeman and James Watts Collection, 1918-1988, Collection No. MS0803.UA. Washington, DC: George Washington University Special Collections Research Center (https://library.gwu.edu/ead/ms0803.xml) [Accessed July 10, 2017]

27. Naesström M, Blomstedt P, Bodlund O: A systematic review of psychiatric indications for deep brain stimulation, with focus on major depressive and obsessive-compulsive disorder. Nord J Psychiatry 70:483-491, 2016

28. Nijensohn DE: Prefrontal lobotomy on Evita was done for behavior/personality modification, not just for pain control. Neurosurg Focus 39(1):E12, 2015

29. Nijensohn DE, Savastano LE, Kaplan AD, Laws ER Jr: New evidence of prefrontal lobotomy in the last months of the illness of Eva Perón. World Neurosurg 77:583-590, 2012

30. Nuttin B, Wu H, Mayberg H, Hariz M, Gabriëls L, Galert T, et al: Consensus on guidelines for stereotactic neurosurgery for psychiatric disorders. J Neurol Neurosurg Psychiatry 85:1003-1008, 2014
31. Park RJ, Singh I, Pike AC, Tan JO: Deep brain stimulation in anorexia nervosa: hope for the hopeless or exploitation of the vulnerable? The Oxford Neuroethics Gold Standard Framework. Front Psychiatry 8:44, 2017

32. Phillips M: The lobotomy files: one doctor's legacy. Wall Street Journal. December 12, 2013 (https://www. wsj.com/articles/the-lobotomy-files-one-doctor8217slegacy-1386804524) [Accessed July 10, 2017]

33. Plath S: The Bell Jar. New York: HarperCollins, 2005

34. Pressman JD: Richard H. Shryock medal essay. Sufficient promise: John F. Fulton and the origins of psychosurgery. Bull Hist Med 62:1-22, 1988

35. Robison RA, Taghva A, Liu CY, Apuzzo ML: Surgery of the mind, mood, and conscious state: an idea in evolution. World Neurosurg 80:S2-S26, 2013

36. Rovit RL, Couldwell WT: A man for all seasons: W.W. Keen. Neurosurgery 50:181-190, 2002

37. Rowland LP: Walter Freeman's psychosurgery and biological psychiatry: a cautionary tale. Neurol Today 5:70-72, 2005

38. Scoville WB: Selective cortical undercutting as a means of modifying and studying frontal lobe function in man; preliminary report of 43 operative cases. J Neurosurg 6:65-73, 1949

39. Sheehan JP, Patterson G, Schlesinger D, Xu Z: Gamma Knife surgery anterior capsulotomy for severe and refractory obsessive-compulsive disorder. J Neurosurg 119:1112-1118, 2013

40. Shutts D: Lobotomy: Resort to the Knife. New York: Van Nostrand Reinhold, 1982

41. Widge AS, Ellard KK, Paulk AC, Basu I, Yousefi A, Zorowitz S, et al: Treating refractory mental illness with closedloop brain stimulation: progress towards a patient-specific transdiagnostic approach. Exp Neurol 287:461-472, 2017

42. Williams T: Suddenly Last Summer and Other Plays. London: Penguin Books, 2010

\section{Disclosures}

The authors report no conflict of interest concerning the materials or methods used in this study or the findings specified in this paper.

\section{Author Contributions}

Conception and design: Caruso. Acquisition of data: Caruso. Analysis and interpretation of data: Caruso. Drafting the article: Caruso. Critically revising the article: both authors. Reviewed submitted version of manuscript: both authors. Approved the final version of the manuscript on behalf of both authors: Caruso. Administrative/technical/material support: Sheehan. Study supervision: Sheehan.

\section{Correspondence}

James P. Caruso, Department of Neurological Surgery, University of Virginia Health System, Box 800212, Charlottesville, VA, 22908. email: jpc9j@virginia.edu. 